\title{
Doctors' attitudes in the situation of delivering bad news: patients' experience and expectations
}

\author{
Krzysztof Sobczak, Katarzyna Leoniuk
}

Department of Sociology of Medicine and Social Pathology, Medical University of Gdansk, Poland

Submitted: 17 July 2019

Accepted: 2 October 2019

Arch Med Sci

DOI: 10.5114/aoms/112756

Copyright $\odot 2020$ Termedia \& Banach

\author{
Corresponding author: \\ Krzysztof Sobczak PhD \\ Department of Sociology \\ of Medicine and Social \\ Pathology \\ Medical University of Gdansk \\ 15 Tuwima Str. \\ 80-210 Gdansk, Poland \\ E-mail: ksobczak@gumed.edu.pl
}

\begin{abstract}
Introduction: The purpose of our research was to find out patients' preferences concerning their doctors' attitudes and behaviour as they deliver bad news to them.

Material and methods: In national research conducted from February to October 2017 using the CAWI (computer-assisted web interview) technique, we studied the statements of 314 adult patients who had received bad medical news from their doctors. Seventy-nine per cent of them were women and $21 \%$ were men. Fifty-nine per cent had higher education and 33\% had secondary education. A specially designed closed question survey was used as a tool to collect the data.

Results: Most of the patients (59.6\%) expected a doctor-patient relationship based on partnership and collective decisions concerning further treatment. Patients wanted their doctors to be honest with them, to provide them with solid information and an opportunity to ask questions and discuss the suggested solutions. Less than 2 out of 10 patients expected "an empathy specialist". The patients who evaluated their doctors' behaviour and the way bad news was delivered to them negatively were more likely to change doctors or terminate their treatment.

Conclusions: The doctor-patient relationship when an unfavourable diagnosis is being communicated is an important aspect, which defines the way people who participate in this difficult situation behave and communicate. Doctors' behaviour during DBN should meet the patients' expectations. Such an attitude guarantees trust towards doctors and results in more positive evaluations on them. Most importantly, it translates directly into the patients' therapeutic behaviours and treatment effects.
\end{abstract}

Key words: bad news, truth disclosure, doctor-patient relationship, communication, patient preferences.

\section{Introduction}

Delivering bad news (DBN) is one of the most difficult responsibilities a doctor must face $[1,2]$. Many reports indicate solutions thanks to which the problems resulting from the need to not only deliver bad news but also to receive it can be reduced [3-6]. We know that effective communication on the part of the doctor should be based on empathy and a personalised attitude to the patient [7-11]. Such contact has a positive impact on the therapeutic process and the patients' general condition $[12,13]$. However, it must not be forgotten that the doctor-patient relationship is one of the factors that are fundamental to 
the character of medical communication. This relationship is always set in a particular socio-cultural context. There are few reports that analyse the actual connections between these variables in a situation when bad news is communicated. There is also a severe shortage of research verifying the applicability of the classic sociological models in the face of the dynamics of today's changes in the doctor-patient relationship in the context of DBN [14].

The conclusions from our previous research [15] analysing the problems of delivering bad news from the doctor's perspective became our motivation to explore the issue from the patient's point of view. The purpose of our research was to gain knowledge on the experiences and expectations of the patients who have heard bad news from their doctors. We wanted to find out the patients' opinions on their doctors' attitudes and behaviour as well as the model of the doctorpatient relationship that is preferable to them. We hope that the results we obtain could be used for more effective doctor training and will contribute to the perspective of a personalised attitude towards the patient.

For the purpose of our research, we have assumed the definition of bad medical news understood as a diagnosis of a disease which is connected with long-lasting or relatively long-lasting changes in one's body, requiring constant or long-term treatment, or is connected with pain management therapy (e.g. diabetes, coronary disease, and cancer, as well as mental illnesses and genetic diseases or untreatable terminal diseases).

\section{Material and methods}

In the retrospective study conducted using the CAWI (computer-assisted web interview) technique, during the period between February and October 2017, statements were collected from 314 respondents. The study was voluntary and anonymous, with purposive sampling. In order for us to reach patients who have been given bad news, 19 foundations and associations posted information on their websites and social media profiles. It contained an invitation to participate in the study, the sampling criteria, and a link for the e-survey. We also posted the same information on 30 selected online forums administrated by websites connected with health. The study, which was of an inclusive character, involved adults. The criterion of having received bad news was verified based on the data obtained in the open-ended question concerning the disease classification. We posted the survey on a professional research website (e-badania.pl) which guarantees data safety and the respondents' anonymity. We did not gather any of the participants' sensitive or personal data ourselves. When building this research tool, we took into account the experience we had gained in earlier studies on this subject [15]. Before the research phase was commenced, the questionnaire underwent assessment and methodological consultation. In the final version, we asked the patients 16 closed questions and 3 semi-open questions. The part of the survey concerning the respondent alone consisted of 8 closed questions, 2 semi-open questions, and 1 open question concerning the disease entity. The doctor-patient relationship typology was prepared based on the analysis of literature, which took into account classical and contemporary sociological doctor-patient relationship models [16-19]. Their description was included in the survey, together with a request for the respondents to point to the one that was the closest to their expectations.

We used a specially designed e-questionnaire, approved by the Independent Bioethics Commission for Research at the Medical University of Gdansk (NKBBN/475/2016), as our research tool. In the process of creating the questionnaire, we took into account the experience gathered by us in previous research projects concerning the physician-patient relationship.

The instructions that precede the survey contain information about its purpose and format, as well as the possibility to withdraw from it at any stage. Therefore, when analysing the results, we used only the questionnaires that were completed in full.

SPSS v. 26.0 software was used for statistical analysis. The statements of the respondents were correlated with sociodemographic variables, the types of their diseases, and medical variables (doctor's specialisation, the place where they were in contact with their doctors, and the source of payment for their consultation). Pearson's $\chi^{2}$ test was used for the analysis of the correlation between the discontinuous variables and the statistic heterogeneity of the groups. We have assumed the difference for $p<0.05$ as statistically important.

The research method that was used (CAWI) affected the sociodemographic characteristics of the investigated group. Just as in other studies of this type, there was an overrepresentation of women, who constituted $79 \%$ of the study group, and respondents with higher education (59\%). The sample turned out to be diverse in terms of age and marital status. Health variables (type of disease) as well as medical variables (doctor's specialisation) diversified the study group significantly (Table I). 
Table I. Characteristics of respondents $(n=314)$

\begin{tabular}{|c|c|}
\hline Category & $n(\%)$ \\
\hline \multicolumn{2}{|l|}{ Gender } \\
\hline Female & $248(79)$ \\
\hline Male & $66(21)$ \\
\hline \multicolumn{2}{|l|}{ Education } \\
\hline Primary education & $4(1.5)$ \\
\hline Lower-secondary education & $4(1.5)$ \\
\hline Vocational education & $15(5.0)$ \\
\hline Secondary education & $105(33.0)$ \\
\hline Higher education & $186(59.0)$ \\
\hline \multicolumn{2}{|l|}{ Place where the bad news was delivered } \\
\hline Public clinic & $47(15.0)$ \\
\hline Public polyclinic & $45(14.5)$ \\
\hline Private polyclinic & $20(6.5)$ \\
\hline Private clinic & $8(2.5)$ \\
\hline Private doctor's office & $29(9.0)$ \\
\hline Hospital & $165(52.5)$ \\
\hline \multicolumn{2}{|l|}{ Type of disease } \\
\hline Tumours & $119(38.0)$ \\
\hline Nervous system diseases & $61(19.0)$ \\
\hline $\begin{array}{l}\text { Disorders of pancreatic internal } \\
\text { secretion }\end{array}$ & $29(9.0)$ \\
\hline $\begin{array}{l}\text { Blood disorders and cardiovascular } \\
\text { diseases }\end{array}$ & $26(8.0)$ \\
\hline Musculoskeletal diseases & $18(6.0)$ \\
\hline Genitourinary system's diseases & $14(5.0)$ \\
\hline Mental and behavioural disorders & $9(3.0)$ \\
\hline Skin diseases & $9(3.0)$ \\
\hline Eye diseases & $8(2.5)$ \\
\hline Other & $21(6.5)$ \\
\hline \multicolumn{2}{|l|}{ Marital status } \\
\hline Single & $111(35.5)$ \\
\hline Married & $167(53.0)$ \\
\hline Widow/widower & $17(5.5)$ \\
\hline Divorced & $19(6.0)$ \\
\hline \multicolumn{2}{|l|}{ Age } \\
\hline $18-30$ years & $78(25.0)$ \\
\hline $31-40$ years & $84(27.0)$ \\
\hline $41-50$ years & $65(21.0)$ \\
\hline $51-60$ years & $44(14.0)$ \\
\hline 61 years and more & $43(13.0)$ \\
\hline
\end{tabular}

Table I. Cont.

\begin{tabular}{|c|c|}
\hline Category & $n(\%)$ \\
\hline \multicolumn{2}{|l|}{ Visit payer } \\
\hline National Health Fund & $254(81.0)$ \\
\hline Insurance company & $5(1.5)$ \\
\hline Own resources & $46(14.5)$ \\
\hline I don't remember & $9(3.0)$ \\
\hline \multicolumn{2}{|l|}{ Medical specialisation } \\
\hline Neurologist & $54(17.0)$ \\
\hline Haematologist & $41(13.0)$ \\
\hline Oncologist & $37(12.0)$ \\
\hline Surgeon & $29(9.0)$ \\
\hline Gynaecologist & $25(8.0)$ \\
\hline Endocrinologist & $21(7.0)$ \\
\hline General physician & $21(7.0)$ \\
\hline Rheumatologist & $10(3.0)$ \\
\hline Cardiologist & $10(3.0)$ \\
\hline Other: psychiatrist, ger & $66(21.0)$ \\
\hline
\end{tabular}

\section{Results}

To gather the opinions on the quality of communication when bad news is being delivered, we asked patients about their experiences of contact with their doctors. We also tried to determine what type of doctor-patient relationship is preferred by patients in such a situation.

\section{Possibility to ask the doctor clarifying questions}

First, we wanted to determine whether the patients had a chance to ask their doctors questions so that the information they had just heard could be clarified. Most of the study group (70\%) confirmed that this was possible for them. On the other hand, $20 \%$ of the patients admitted that their doctors did not give them a chance to do this, while the rest of the patients did not remember if they had had such a chance.

Most of the participants (83\%) who used private health care (consultation at a private polyclinic, clinic, hospital, or doctor's office) had the chance to ask their doctors questions, while patients of public facilities (public clinics, polyclinics, and hospitals) were given such a chance by doctors less frequently (67\%). The differences that occurred in both groups turned out to be statistically significant $\left(\chi^{2}=6.454 ; \mathrm{df}=2 ; p=0.04\right)$.

The place where the patient met the doctor (Table II) turned out to be another medical vari- 
Table II. The location where the consultation took place and whether it was possible to ask the doctor questions about an unfavourable diagnosis $(n=314)$

\begin{tabular}{|c|c|c|c|c|c|}
\hline \multirow{2}{*}{$\begin{array}{l}\text { Was it possible to ask } \\
\text { the doctor questions } \\
\text { concerning the diagnosis? }\end{array}$} & \multicolumn{4}{|c|}{ The place where the unfavourable diagnosis was delivered } & \multirow[t]{2}{*}{ Total } \\
\hline & $\begin{array}{l}\text { Clinic - } \\
\text { private and } \\
\text { public, } n(\%)\end{array}$ & $\begin{array}{l}\text { Polyclinic - } \\
\text { private and } \\
\text { public, } n(\%)\end{array}$ & $\begin{array}{c}\text { Doctor's office* }^{*} \\
\text { private, } n(\%)\end{array}$ & $\begin{array}{l}\text { Hospital* - } \\
\text { public, } n(\%)\end{array}$ & \\
\hline "Yes" & $39(70.9)$ & $49(75.4)$ & $26(89.7)$ & $106(64.2)$ & $220(70.1)$ \\
\hline "No" or "I do not remember" & $16(29.1)$ & $16(24.6)$ & $3(10.3)$ & $59(35.8)$ & $94(29.9)$ \\
\hline Total & $55(100.0)$ & $65(100.0)$ & $29(100.0)$ & $165(100.0)$ & $314(100.0)$ \\
\hline \multicolumn{6}{|c|}{ Statistics: $\chi^{2}=8.869 ; \mathrm{df}=3 ; p=0.031$} \\
\hline
\end{tabular}

able that had an impact on the possibility to ask questions. In $90 \%$ of cases, patients whose consultations took place in polyclinics declared that they had had such a chance. Hospitalised patients were the least likely to mention the possibility to ask clarifying questions.

When closing the analysis of the first issue, it is worth emphasising that we discovered a correlation between the possibility to ask the doctor questions and the patient continuing their treatment by him or her (statistics: $\chi^{2}=35.608$; $\mathrm{df}=4$, $p<0.01$ ). As many as $85 \%$ of patients who continued treatment with the doctor who had delivered bad news to them were people who had a chance to ask questions. On the other hand, among those who changed doctors or decided to discontinue their treatment, $67 \%$ were patients whose as sessment of the possibility to ask questions when the diagnosis was delivered was negative.

\section{Patients' need for a type of detailed information}

Specifying the problems that were most frequently mentioned by patients during their conversations with their doctors after having received bad news was another interesting issue for us. Most frequently, the participants of the study asked about further treatment methods and directions (55\%). Less than half of the patients wanted to obtain information about the diagnosed disease entity and the consequences connected with it (46.5\%). Forty-three per cent of patients asked questions about further prognoses and their chances of recovery. Fewer participants were interested in information about the applied diagnostic methods (18\%) or the doctor indicating additional sources of information about the disease (8\%).

\section{A chance for the patient to respond to the information he or she has heard from the doctor}

The results that were obtained in relation to the possibility for the patients to express their own opinions on the methods of treatment offered by the doctors indicate that the experiences of the participants of the study were relatively ambivalent. Exactly $34 \%$ of patients had positive opinions about such a possibility, while 15\% of the participants were definitely satisfied and $29 \%$ were rather satisfied. Dissatisfied patients constituted $40 \%$ of the study group. Among them, $14 \%$ were definitely dissatisfied while $26 \%$ were rather dissatisfied. The remaining $16 \%$ were patients who had difficulty evaluating the possibility of expressing their own opinions.

Just like with the possibility to ask questions, expressing one's opinion on the treatment methods also correlates positively with continuing therapy with the specialist who has delivered bad news (statistics: $\chi^{2}=16.024 ; d f=4 ; p=0.003$ ). Sixty-one per cent of those who had a positive opinion on this aspect of their communication with their doctors continued treatment with them. On the other hand, the respondents whose opinion on the possibility to express their opinions on the treatment method was negative changed doctors more frequently or did not begin further treatment (62\%).

\section{Experiencing the doctor's understanding and care}

More than half of the participants felt that when the doctor was delivering bad news to them he or she was honest with them (76.5\%), did not invade their privacy (62\%), and was trustworthy (53.5\%). The respondents felt that the doctors had prepared for the conversation with them relatively rarely (28\%). Only $35 \%$ of the respondents claimed that they felt that their doctors cared about their emotional condition during DBN (Table III).

Men were more likely to claim that the doctor tried to soothe their nerves (42\%) than women (37\%; statistics: $\chi^{2}=6.554 ; \mathrm{df}=2 ; p=0.038$ ).

Feeling that the doctor focused on the participant of the study completely was reported by patients who used private medical services more often $(56 \%)$ than patients of public facilities ( $46 \%$; 
Table III. Patients' perception of the doctors' attitudes while delivering the unfavourable diagnosis $(n=314)$

\begin{tabular}{|lccc|}
\hline $\begin{array}{l}\text { When the unfavourable diagnosis was being delivered, } \\
\text { I felt that the doctor: }\end{array}$ & $\begin{array}{c}\text { Yes, } \\
n(\%)\end{array}$ & $\begin{array}{c}\text { No, } \\
n(\%)\end{array}$ & $\begin{array}{c}\text { I do not remember, } \\
n(\%)\end{array}$ \\
\hline was completely focused on me and my problem & $150(48.0)$ & $126(40.0)$ & $38(12.0)$ \\
\hline was interested in my physical and mental state & $130(41.0)$ & $156(50.0)$ & $28(9.0)$ \\
\hline respected my privacy & $194(62.0)$ & $95(30.0)$ & $25(8.0)$ \\
\hline seemed trustworthy & $168(53.5)$ & $122(39.0)$ & $24(7.5)$ \\
\hline tried to soothe my nervousness & $121(38.5)$ & $151(48.0)$ & $42(13.5)$ \\
\hline cared about my condition & $110(35.0)$ & $160(51.0)$ & $44(14.0)$ \\
\hline was honest with me & $240(76.5)$ & $39(12.5)$ & $35(11.0)$ \\
\hline had prepared for the conversation with me & $87(28.0)$ & $146(46.0)$ & $81(26.0)$ \\
\hline
\end{tabular}

Table IV. Patients' perception and the possibility to ask questions during the delivery of the unfavourable diagnosis $(n=314)$

\begin{tabular}{|c|c|c|c|}
\hline \multirow[t]{2}{*}{$\begin{array}{l}\text { When the unfavourable diagnosis was } \\
\text { being delivered, I felt that the doctor: }\end{array}$} & \multicolumn{2}{|c|}{$\begin{array}{l}\text { Was it possible to ask the doctor questions when } \\
\text { the diagnosis was being delivered? }\end{array}$} & \multirow{2}{*}{$\begin{array}{c}\text { Statistics } \\
\mathrm{df}=2 ; \\
p<0.01 ; \chi^{2}\end{array}$} \\
\hline & “Yes", n (\%) & “No" or “I do not remember”, $n$ (\%) & \\
\hline was completely focused on me and my problem & 60 & 18 & 55.030 \\
\hline was interested in my physical and mental state & 53 & 14 & 52.818 \\
\hline respected my privacy & 72 & 37 & 36.012 \\
\hline seemed trustworthy & 68 & 20 & 60.188 \\
\hline tried to soothe my nervousness & 50 & 12 & 52.699 \\
\hline cared about my condition & 44 & 13 & 39.649 \\
\hline was honest with me & 82 & 63 & 15.599 \\
\hline had prepared for the conversation with me & 35 & 10 & 40.418 \\
\hline
\end{tabular}

statistics: $\left.\chi^{2}=7.497 ; \mathrm{df}=2 ; p=0.024\right)$. We noticed a confirmation of this tendency when we correlated the participants' impressions with the source of the payment covering the cost of the consultation. Patients who paid for their consultations themselves reported that their problem was more focused on (55\%) than in the case of those who went to free consultations (46\%; statistics: $\chi^{2}=8.865 ; \mathrm{df}=2 ; p=0.012$ ).

We found a correlation of the same character when analysing patients' statements on their impression of the doctor's honesty. Patients who used private health care felt their doctors were honest more frequently (88\%) than those in public facilities (74\%; statistics: $\chi^{2}=6.134$; $d f=2$; $p=0.047)$.

The possibility to ask the doctor questions and the sense of understanding and care

We adopted the possibility to ask the doctor questions during DBN as an independent variable, and then correlated the respondents' answers with their subjective impressions connected with the doctors' attitudes. We noticed statistically significant differences in reference to all the categories of impressions proposed in the study. Therefore, the possibility to ask questions accompanied the positive impressions connected with the doctor's behaviour. The most significant differences were connected with the patient seeing the doctor as trustworthy and focusing on his or her problem. Respondents who could ask their doctors questions provided positive evaluations concerning their impressions of the doctor's behaviour 3 times more often (Table IV).

\section{Patients' preferences concerning their relationships with their doctors}

To determine which relationships with doctors were preferred by the patients, we used the description of selected relationship models and asked the participants to choose the one that was the most preferable to him or her. The model based on partnership was chosen the most fre- 
Table V. Patients' preferences concerning their relationships with their doctors

\begin{tabular}{|c|c|c|c|}
\hline Model description & Model name & Patient's role & $n(\%)$ \\
\hline $\begin{array}{l}\text { The doctor manages my entire treatment, takes care of me, does not } \\
\text { shift the responsibility to take the decision on to me, takes the full } \\
\text { responsibility for the decision and limits our conversations on my } \\
\text { condition to the minimum. }\end{array}$ & Paternalistic & Passive & $16(5.1)$ \\
\hline $\begin{array}{l}\text { The doctor is sure that what he or she is doing is right. In our direct } \\
\text { contact, he or she focuses on facts and does not reveal his or her } \\
\text { feelings. When asked a question, he or she gives a matter-of-fact and } \\
\text { comprehensive answer, while remaining reserved and professional. }\end{array}$ & Informative & Active & $59(18.8)$ \\
\hline $\begin{array}{l}\text { The doctor talks me through the phases of the treatment, prognosis, } \\
\text { the need to do more tests, and have more consultations in detail. } \\
\text { He or she allows me to participate in the decision about my further } \\
\text { treatment and asks for my opinion. }\end{array}$ & $\begin{array}{c}\text { Based on } \\
\text { partnership }\end{array}$ & Collective & $187(59.6)$ \\
\hline $\begin{array}{l}\text { The doctor takes my feelings into account, adjusts the communication } \\
\text { to my mood and expectations. He or she frequently shows support, } \\
\text { offers consolation, and does not limit our conversation to medical } \\
\text { subjects. I feel that the doctor cares about me. }\end{array}$ & $\begin{array}{c}\text { Based on } \\
\text { dialogue and } \\
\text { empathy }\end{array}$ & Emotive & $52(16.6)$ \\
\hline
\end{tabular}

quently. $60 \%$ of responders indicated it. Less than one-fifth of the study group (19\%) chose the informative model based on thorough and comprehensive medical information, while $16 \%$ of the respondents preferred the model based on dialogue and empathy, which emphasised the emotional aspect of the relationship. The paternalistic model turned out to be chosen the least frequently: only $5 \%$ of the respondents indicated it as their most preferable choice.

When analysing the respondents' statements, we noticed the impact of sociodemographic variables like age $\left(\chi^{2}=10.354 ; \mathrm{df}=3 ; p=0.016\right)$ and gender $\left(\chi^{2}=8.648 ; \mathrm{df}=3 ; p=0.034\right)$ on the preferred model of the relationship with one's doctor. The model based on partnership was most frequently indicated by people under 40 years old $(67 \%)$, compared to the patients who were 41 years old or more $(51 \%)$. In spite of the differences, it is worth emphasising that the model based on partnership turned out to be the most popular in both age groups. The patients who were 41 years old or more were 3 times more likely to choose the paternalistic model (8\%), compared to the younger respondents (2.5\%). Apart from that, older respondents were more likely to choose the informative model $(16 \%$ - respondents aged 18-40 years, $22 \%$ - people who were 41 years old or older). The results concerning the model based on dialogue and empathy turned out to be the most similar because it was chosen by $19 \%$ of the older respondents and $14 \%$ of the younger ones.

The paternalistic model [16] was four times more likely to be chosen by men (12\%) than by women (3\%). The model based on partnership [18], on the other hand, was preferred by women more frequently. It was chosen by $61 \%$ of the female respondents and $54 \%$ of the male ones. Women were also a little more likely to choose the infor- mative model [19] than men (19\% vs. $16 \%$, respectively). The model based on dialogue and empathy turned out to be the least diversifying one, indicated by $16 \%$ of women and $16.7 \%$ of men [19].

\section{Discussion}

Many reports suggest that obtaining knowledge on the ways of delivering bad news preferred by patients reduces their mental suffering and affects the results of the treatment $[5,11,12]$. Our previous studies have confirmed these conclusions. They revealed that the doctors' behaviour and the way they deliver bad news translate into the therapeutic interventions. The patients whose assessments of their doctors' attitudes when delivering bad news were negative were more likely to discontinue treatment or change doctors [20]. Therefore, it is important to understand the factors that determine communication with the doctor on the part of the patient [21]. Because of this, the second part of our analyses is focused on investigating the patients' preferences concerning their relations with doctors when bad news is being delivered to them.

The results we received concerning the patients' expectations when it comes to their active participation in the decision-making process concerning the type and form of further treatment correspond to those received by other researchers. The patients who revealed that their doctors made it possible for them to ask questions were 3 times more likely to provide positive evaluations of their doctors' behaviour, and a great majority of them chose to continue their treatment with this doctor. Among others, this image corresponds with the conclusions that were obtained when investigating cancer patients' preferences. They expected personalised care provided by experts who would be willing to answer their questions [11, 22]. 
We also received results that were analogous to what was revealed in other studies when we analysed the patients' opinions on the possibility to freely express their opinions on the diagnostic and treatment methods offered by their doctors. The patients who were not given such an opportunity by their doctors were more likely (62\%) to discontinue treatment and change doctors. On the other hand, creating room for the patient's participation in taking medical decisions activates him or her and results in him or her being more engaged in the treatment process [23]. Most patients, not just in our study, declare they want to be involved in the decision-making process [3].

We also asked the patients to assess the attitudes and behaviour of doctors during DBN in the emotive context. Many studies emphasise the fact that a doctor's empathic attitude correlates with a better understanding of the patient [24]. Therefore, it is of key significance to the doctor-patient relationship [7]. It has a positive impact on the diagnosis accuracy, improves the quality of life, and reduces the patient's emotional pain [25-27]. Research also shows that empathic doctors receive better evaluations from their patients [8].

In the results that we obtained, as many as $50 \%$ of the patients revealed that in their opinion the doctor was not interested in their physical and mental condition. Most of the respondents had the impression that the doctors were not bothered by their emotional state (46\%) and did not provide them with support by trying to soothe their nervousness (48\%). In spite of these opinions, more than $50 \%$ of patients admitted that the doctors seemed trustworthy (53.5\%). Our findings about these preferences may suggest that when bad news is being delivered, a significant proportion of the patients do not expect empathy from their doctors. To pursue this perspective, we asked the respondents directly about their preferences concerning their relationships with doctors. For this, we used a matrix of the typology of attitudes in the doctor-patient relationships (Table V). Its structure referred to the classic and contemporary sociological models: Parsons's paternalistic model [16] as well as Szasz and Hollender's typological model [17], Pierloot's concept [19] - The Communication Model (which we have called "informative") as well as The Model of Human Encounter (which we have been referring to as the one "based on dialogue and empathy") and Balint's model based on partnership [18].

The results we received did not overlap with the conclusions, which suggests that patients usually expect a doctor who behaves like an "empathy specialist" in the DBN situation [28]. In our study, the number of patients who declared a pref- erence for such an emotive relationship was similar to the ones who chose the informative model (18.8\%). A relationship based on emotions, which consists of an attempt to understand the situation in which the patient has found him or herself, was not the most frequently expected attitude $(16.6 \%)$. It was similar to German research [29]. The most frequently expected doctors' attitude was a relationship based on partnership and the principle of collectivism. Most of the patients wanted to get to know the details about their illnesses and to participate in the decision concerning treatment. The patients expected their doctors to answer their questions and take their opinions into account. Other authors who have analysed this problem seem to share our observations $[3,4]$. However, it needs to be emphasised that in the Davison et al. study, the difference between the preference for the active (43\%) and collective (47\%) participation turned out to be much smaller than in the results that we obtained [4].

We also obtained important results concerning the received correlations between the preferred models of the doctor-patient relationship and independent variables. The least frequently chosen paternalistic model (5.1\%) was mostly indicated by older patients and men. The informative model (18.8\%) was most frequently chosen by women and patients who were over 40 years old. Women and patients who were at least 40 years old usually preferred the model based on partnership. The choice of the relationship based on dialogue and empathy turned out to be the least diversified in terms of the women's and men's choices. These results correspond with the results obtained by other authors and the results of our previous studies. Younger patients, women, and the more educated ones are more likely to expect detailed information and encouragement to participate in decisions on further diagnostic and therapeutic processes $[4,15,30]$. It is worth emphasising that in the analysis of preference distribution in the patients who indicated the model based on dialogue and empathy, we did not discover a difference in choices based on gender.

From the sociological point of view, the relationship between a doctor and patient goes beyond the interaction between two people [14]. Its dynamic is influenced by social factors that form a labyrinth of interpenetrating connections. From changes in health awareness connected with universal access to medical information [31], through better access to medical care, codification of patient rights, to the changes in the role of a doctor and replacing the attending physician with an interdisciplinary therapeutic team. Some of the variables determine not only the quality but also the type of the doctor-patient relationship. Our 
research showed that the patients who attended private consultations could count on a more active and collective relationship with their doctors more frequently than the remaining patients. Eighty-three per cent of these patients pointed to the possibility to ask questions, $56 \%$ said that they were satisfied by the attention that the doctors had given them, while $88 \%$ thought that the doctors were being honest with them when delivering the bad news to them.

It is worth emphasising that the results that we obtained should be regarded in relation to a particular social and cultural context [32]. The study was conducted in Polish. The research technique that was applied (CAWI) brought about a typical overrepresentation of women and people with higher education. These variables may have a significant impact on the patients' expectations and, therefore, condition the mutual relationships.

In conclusion, our research revealed that, according to patients, when bad news is being delivered, the model of the doctor-patient relationship based on partnership is the most preferable. In this difficult situation, patients usually preferred the collective relation based on honest and reliable information about their condition. They also wanted to be able to ask questions, discuss the offered methods of treatment, and participate in the decision-making process. Less than 2 in 10 patients expected the doctor to establish an emotive relationship with them and preferred an "empathy specialist".

The way that bad medical news was delivered to the patients also turned out to be significant for the patients' decisions to continue or discontinue treatment. The patients whose doctors made it possible for them to actively participate in making the decision had higher opinions of the course of the meeting and were more diligent when it came to following the settlements concerning the treatment. Those patients, who negatively evaluated the way in which bad news was delivered to them, were more likely to either change their doctor or discontinue the treatment. Independent variables turned out to be significant factors that affected the evaluation of the doctorpatient relationship and the way the patients received bad news.

\section{Acknowledgements}

We would like to express our gratitude to all patients' associations and foundations and to WP Polska ABC Zdrowie for informing patients about free participation in our research.

\section{Conflict of interest}

The authors declare no conflict of interest.

\section{References}

1. Brown R, Dunn S, Byrnes K, Morris R, Heinrich P, Shaw J. Doctors' stress responses and poor communication performance in simulated bad-news consultations. Acad Med 2009; 84: 1595-602.

2. Cohen L, Baile WF, Henninger E, et al. Physiological and psychological effects of delivering medical news using a simulated physician-patient scenario. J Behav Med 2003; 26: 459-71.

3. Brown VA, Parker PA, Furber L, Thomas AL. Patient preferences for the delivery of bad news the experience of a UK Cancer Centre. Eur J Cancer Care (Engl) 2011; 20: 56-61.

4. Davison BJ, Parker PA, Goldenberg SL. Patients' preferences for communicating a prostate cancer diagnosis and participating in medical decision-making. BJU Int 2004; 93: 47-51.

5. Furber L, Cox K, Murphy R, Steward W. Investigating communication in cancer consultations: what can be learned from doctor and patient accounts of their experience? Eur J Cancer Care (Engl) 2013; 22: 653-62.

6. Ishaque S, Saleem T, Khawaja FB, Qidwai W. Breaking bad news: exploring patient's perspective and expectations. J Pak Med Assoc 2010; 60: 407-11.

7. Bratek A, Bulska W, Bonk M, Seweryn M, Krysta K. Empathy among physicians, medical students and candidates. Psychiatr Danub 2015; 27 Suppl 1: 48-52.

8. Pollak KI, Alexander SC, Tulsky JA, et al. Physician empathy and listening: associations with patient satisfaction and autonomy. J Am Board Fam Med 2011; 24: 665-72.

9. Abazari P, Taleghani F, Hematti S, Ehsani M. Exploring perceptions and preferences of patients, families, physicians, and nurses regarding cancer disclosure: a descriptive qualitative study. Support Care Cancer 2016; 24: 4651-9.

10. Lazarus A. Can we talk? The search for common ground in the doctor-patient relationship. J Med Pract Manage 2013; 29: 152-6.

11. Gebhardt C, Gorba C, Oechsle K, Vehling S, Koch U, Mehnert A. Breaking bad news to cancer patients: content, communication preferences and psychological distress. Psychother Psychosom Med Psychol 2017; 67: 312-21.

12. Zolnierek KB, Dimatteo MR. Physician communication and patient adherence to treatment: a meta-analysis. Med Care 2009; 47: 826-34.

13. Náfrádi L, Kostova Z, Nakamoto K, Schulz PJ. The doctorpatient relationship and patient resilience in chronic pain: a qualitative approach to patients' perspectives. Chronic Illn 2018; 14: 256-70.

14. Namazi H, Aramesh K, Larijani B. The doctor-patient relationship: toward a conceptual re-examination. J Med Ethics Hist Med 2016; 9: 1-6.

15. Sobczak K, Pawłowski L, Pietrzykowska M, Spolak N. Delivering bad news by physicians - Polish reality check. J Med Sci 2016; 85: 172-7.

16. Parsons T. Illness and the role of the physician: a sociological perspective. Am J Orthopsychiatry 1951; 21: 452-60.

17. Szasz TS, Hollender MH. A contribution to the philosophy of medicine; the basic models of the doctor-patient relationship. AMA Arch Intern Med 1956; 97: 585-92.

18. Balint $M$. The doctor, his patient, and the illness. Lancet 1955; 268: 683-8.

19. Pierloot RA. Different models in the approach to the doctor-patient relationship. Psychother Psychosom 1983; 39: 213-24.

20. Sobczak K, Leoniuk K, Janaszczyk A. Delivering bad news: patient's perspective and opinions. Patient Prefer Adherence 2018; 12: 2397-404. 
21. Street RL, Jr., Gordon HS, Ward MM, Krupat E, Kravitz RL Patient participation in medical consultations: why some patients are more involved than others. Med Care 2005; 43: 960-9.

22. Rudolph A, Hilbert A. A novel measure to assess selfdiscrimination in binge-eating disorder and obesity. Int J Obes (Lond) 2015; 39: 368-70.

23. Edwards A, Elwyn G. Inside the black box of shared decision making: distinguishing between the process of in volvement and who makes the decision. Health Expect 2006; 9: 307-20.

24. O'Sullivan DM, Moran J, Corcoran P, O'Flynn S, O'Tuathaigh C, O'Sullivan AM. Medical school selection criteria as predictors of medical student empathy: a cross-sectional study of medical students, Ireland. BMJ Open 2017; 7: e016076.

25. Squier RW. A model of empathic understanding and adherence to treatment regimens in practitioner-patient relationships. Soc Sci Med 1990; 30: 325-39.

26. Beck RS, Daughtridge R, Sloane PD. Physician-patient communication in the primary care office: a systematic review. J Am Board Fam Pract 2002; 15: 25-38.

27. Gelhaus P. The desired moral attitude of the physician: (I) empathy. Med Health Care Philos 2012; 15: 103-13.

28. Martins RG, Carvalho IP. Breaking bad news: patients' preferences and health locus of control. Patient Educ Couns 2013; 92: 67-73.

29. Rudolph I, Seilacher E, Koster MJ, et al. Survey on information needs of cancer patients and their relatives in Germany. Dtsch Med Wochenschr 2015; 140: 43-7.

30. Fan Z, Chen L, Meng L, et al. Preference of cancer patients and family members regarding delivery of bad news and differences in clinical practice among medical staff. Support Care Cancer 2018; 27: 583-9.

31. Lejoyeux M. The doctor-patient relationship: new psychological models. Bull Acad Natl Med 2011; 195: 1477 88.

32. Seifart C, Hofmann M, Bar T, Riera Knorrenschild J, Seifart U, Rief W. Breaking bad news-what patients want and what they get: evaluating the SPIKES protocol in Germany. Ann Oncol 2014; 25: 707-11. 